\title{
Optimization of the total arch replacement technique: Left subclavian perfusion with sequential aortic reconstruction
}

\author{
Qing Li, MD, ${ }^{\mathrm{a}}$ Wei-Guo Ma, MD, PhD, ${ }^{\mathrm{b}}$ and Li-Zhong Sun, MD, ${ }^{\mathrm{b}}$ Xuzhou and Beijing, China
}

\footnotetext{
From the ${ }^{\mathrm{a}}$ Department of Cardiothoracic Surgery, Affiliated Hospital of Xuzhou Medical University, Xuzhou; and ${ }^{b}$ Department of Cardiovascular Surgery, Beijing Anzhen Hospital, Capital Medical University, Beijing, China. Disclosures: The authors reported no conflicts of interest.

The Journal policy requires editors and reviewers to disclose conflicts of interest and to decline handling or reviewing manuscripts for which they may have a conflict of interest. The editors and reviewers of this article have no conflicts of interest.

Received for publication March 12, 2020; revisions received Oct 25, 2020; accepted for publication Nov 18, 2020; available ahead of print Dec 4, 2020.

Address for reprints: Qing Li, MD, Department of Cardiothoracic Surgery, Affiliated Hospital of Xuzhou Medical University, 99 West Huaihai Rd, Xuzhou, Jiangsu 221006, China (E-mail: csqingli@ gmail.com).

J Thorac Cardiovasc Surg 2021;161:e447-51

$0022-5223$

Copyright (c) 2020 The Author(s). Published by Elsevier Inc. on behalf of The American Association for Thoracic Surgery. This is an open access article under the CC BY-NC-ND license (http://creativecommons. org/licenses/by-nc-nd/4.0/).

https://doi.org/10.1016/j.jtcvs.2020.11.110
}

Video clip is available online.

Despite many technical improvements, total arch replacement is still associated with a high risk of stroke and paraplegia, which is largely ascribed to the long duration of hypothermic circulatory arrest (HCA) and cerebral ischemia. ${ }^{1}$ We have optimized our current total arch replacement technique ${ }^{2,3}$ by using left subclavian artery (LSA) cannulation and sequential aortic reconstruction to decrease the time of HCA and cerebral and spinal cord ischemia, which has achieved encouraging preliminary results.

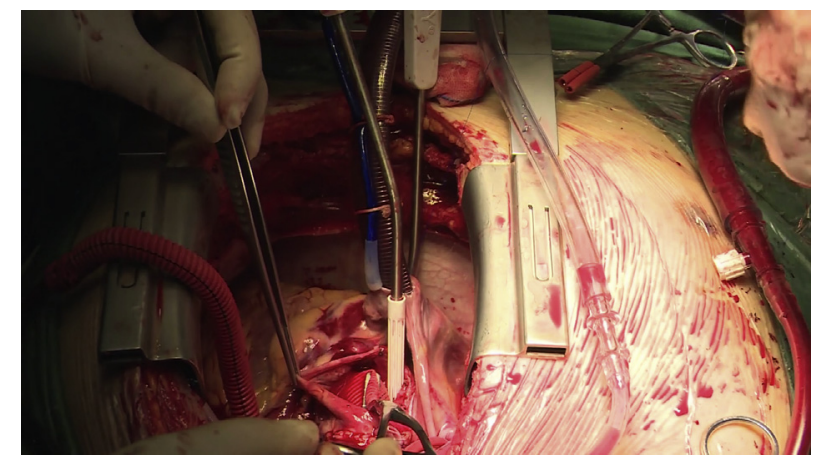

VIDEO 1. Total arch replacement and frozen elephant trunk implantation under hypothermic circulatory arrest using left subclavian artery cannulation and sequential arch reconstruction. Video available at: https://www. jtcvs.org/article/S0022-5223(20)33197-4/fulltext.

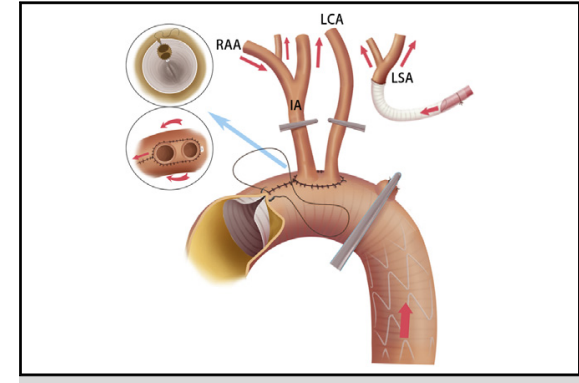

Arch reconstruction under cerebral perfusion via the left subclavian and right axillary arteries.

\section{CENTRAL MESSAGE \\ Cerebral perfusion via the left subclavian and right axillary ar- teries and sequential aortic reconstruction with frozen elephant trunk shorten the cir- culatory arrest time to 3 minutes in total arch repair.}

See Commentaries on pages e453 and $\mathbf{e} 454$.

\section{SURGICAL TECHNIQUES}

The arch branches are mobilized and encircled (Video 1). A trifurcate arterial line is used to connect to the femoral artery (FA), right axillary artery (RAA), and LSA (20F), respectively (Figure 1,A). After heparinization, the FA and RAA, right atrium, and right superior pulmonary vein are directly cannulated to set up cardiopulmonary bypass. In patients with preoperative extremity ischemia, a Dacron graft would be sutured to the FA or RAA for cannulation. Systemic cooling is begun to induce hypothermia by using both femoral and axillary perfusion simultaneously.

The LSA is transected 5-10 mm distal to its arch origin. Its distal portion is connected to the $20 \mathrm{~F}$ arterial line with an 8-mm Dacron graft for cerebral and distal perfusion (Figure 1, B).

When nasopharyngeal temperature reaches $25^{\circ} \mathrm{C}-28^{\circ} \mathrm{C}$, the FA cannula is clamped, and the LCA and innominate artery (IA) are clamped. HCA is instituted. Cerebral perfusion is performed through the RAA and LSA with a flow rate of 


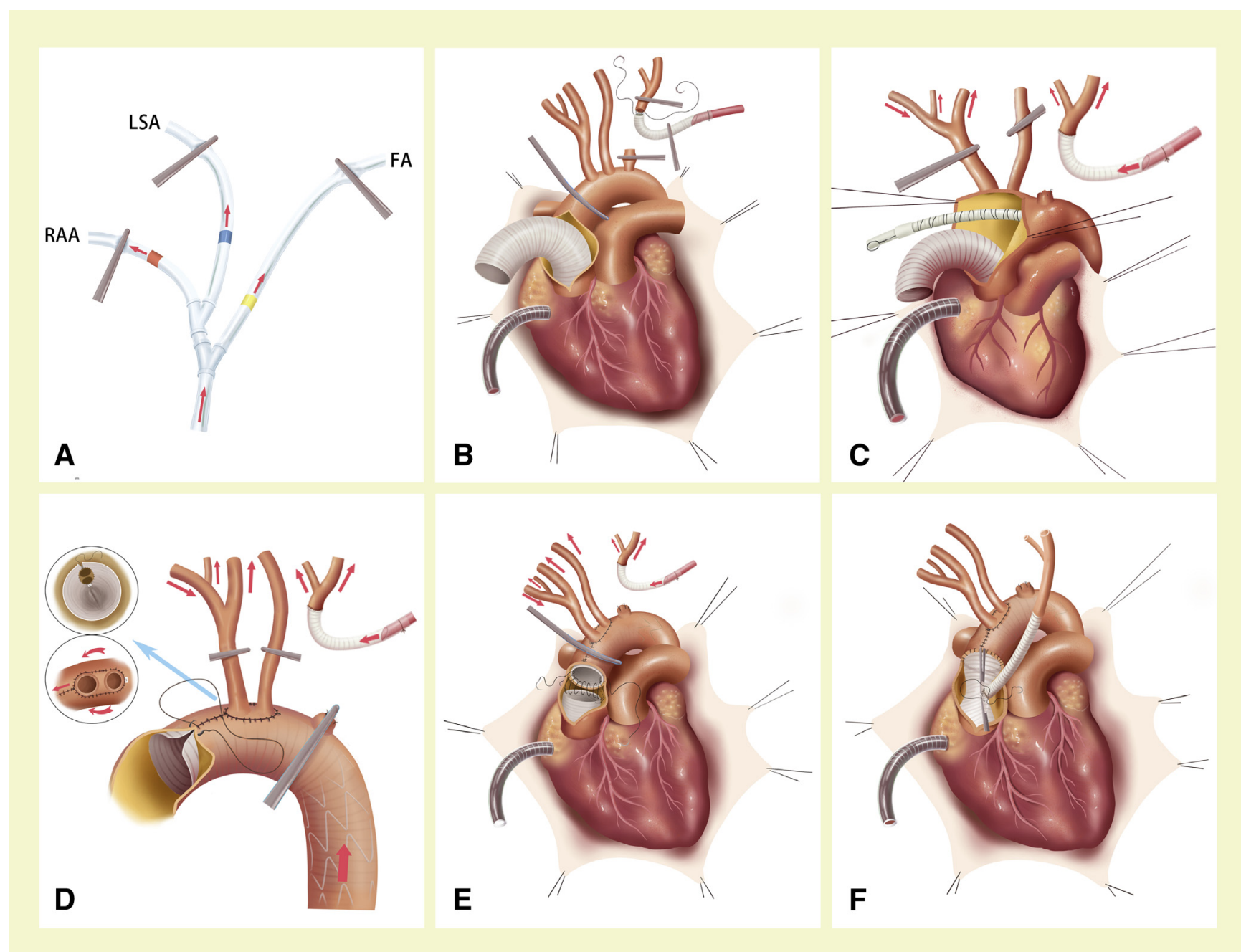

FIGURE 1. Sequential arch reconstruction under hypothermic circulatory arrest and cerebral perfusion via cannulation of the left subclavian artery and right axillary artery. A, A customized trifurcate arterial line is used to connect to the RAA, LSA, and FA. B, The LSA is connected to the arterial line with an 8-mm Dacron graft for cerebral and distal perfusion. C, Under HCA and cerebral perfusion via the left subclavian and right axillary arteries, an FET prosthesis is deployed into the descending aorta. D, The distal aortic arch, together with the proximal unstented graft of the FET located inside, are clamped at the orifice of the left subclavian artery, the clamp on the femoral artery is removed, and HCA is terminated. The left carotid and innominate arteries are reconstructed using a modified en bloc technique. The details of harvesting the aortic patch, the sequence, and direction of placing the stitches are shown in the inset and described in Zhu and colleagues. ${ }^{4} \mathrm{E}$, The innominate and left carotid arteries are declamped. The clamp on the arch is released and moved to the ascending aorta or graft, which is anastomosed to the proximal unstented portion of the FET in an end-to-end fashion. F, The ascending aorta or ascending aortic graft is deaired and unclamped. The left subclavian artery is anastomosed to the ascending aorta or graft using the 8-mm Dacron graft in an end-to-side manner. $L S A$, Left subclavian artery; FA, femoral artery; RAA, right axillary artery.

$8-12 \mathrm{~mL} / \mathrm{kg} / \mathrm{min}$ and a pressure of $50-60 \mathrm{~mm} \mathrm{Hg}$. The anterior wall of arch is incised longitudinally up to the origin of LCA. A frozen elephant trunk (FET) with a 6.5-cm proximal unstented Dacron graft (MicroPort Medical, Shanghai, China) is deployed into the descending aorta (Figure 1,C).

The distal aortic arch, together with the proximal unstented graft of the FET located inside, is clamped at the level of LSA orifice, and the FA is unclamped. Now HCA is terminated. Distal perfusion to spinal cord, viscera, and lower body is resumed through the FA. A patch is harvested containing the orifices of LCA and IA, leaving a 3- to 5-mm rim around, and anastomosed to the proximal unstented portion of the FET, as described previously. ${ }^{4}$ The incised aortic wall is reapproximated to wrap the anastomosis and graft inside (Figure 1,D), which serves as the proximal landing zone of the FET and is helpful for minimizing the risk of problematic postoperative bleeding. 

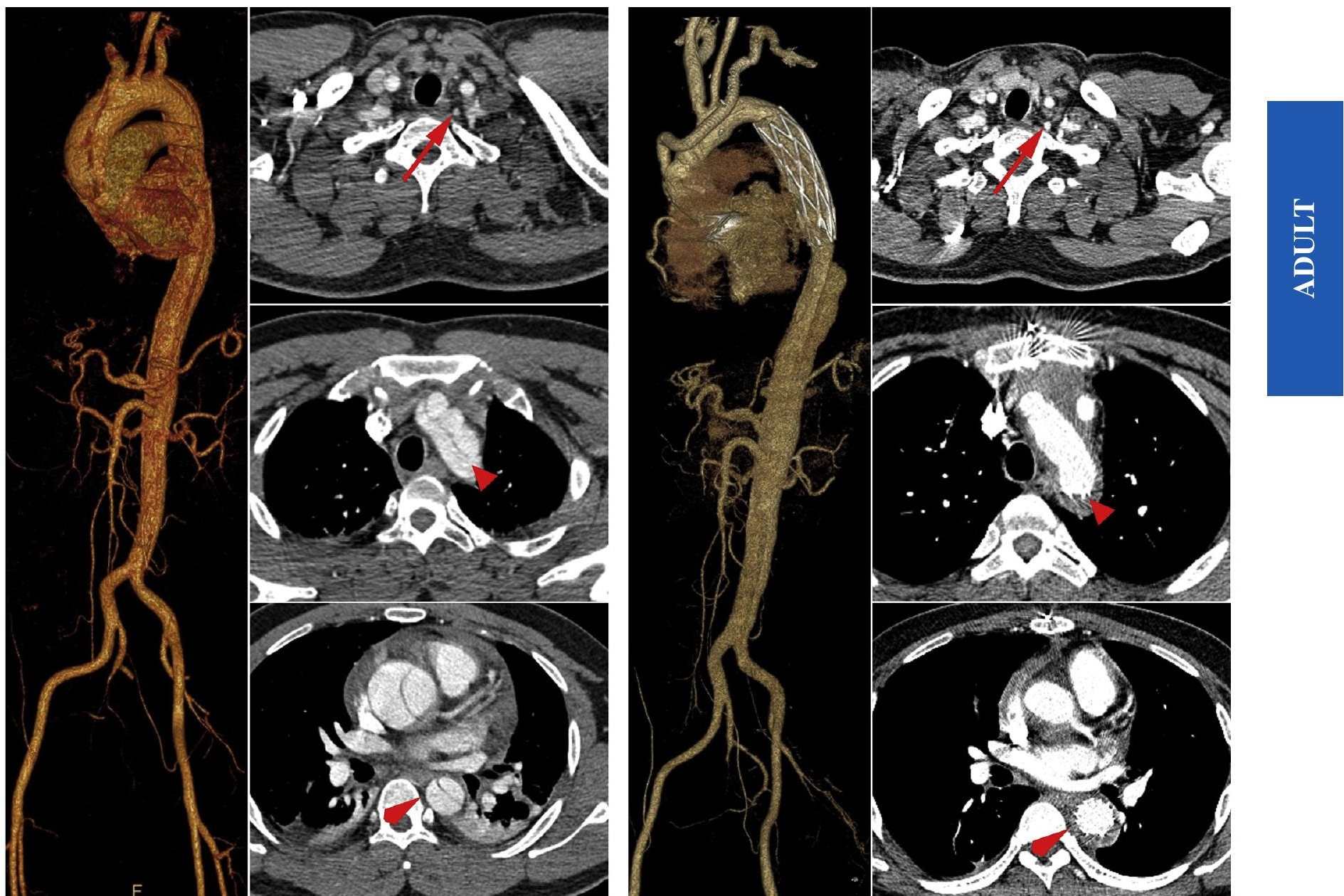

FIGURE 2. In a 36-year-old male patient sustaining an acute type A dissection, preoperative CT angiogram (left) showed a root aneurysm, arch involvement involved by dissection (triangle) and a left vertebral artery (arrow), with intercostal arteries arising from the false lumen (arrowhead). At 3 months after total arch replacement and frozen elephant trunk, CT angiogram showed obliterated false lumen and patent arch branches (right).

The IA and LCA are declamped. The clamp on the arch is released and moved to the ascending aorta (AAo), proximal to the orifice of the IA. Cerebral perfusion is resumed through the LCA and rewarming initiated. The proximal unstented graft of the FET is anastomosed end-to-end to the AAo or ascending aortic graft (Figure 1,E).

The AAo or ascending aortic graft is deaired and declamped. Heart beat returns afterwards. The LSA is reconnected proximally end-to-side to the AAo or ascending aortic graft using the 8-mm Dacron graft (Figure 1, F).

\section{PRELIMINARY RESULTS}

Five patients with acute type A dissection involving the arch were managed with this technique. Four patients had a root aneurysm; 2 had a dominant left vertebral artery; and the intercostal arteries arose from the false lumen in 2 patients (Figure 2). The mean duration of HCA and antegrade cerebral perfusion were $2.6 \pm 0.5$ and $8.8 \pm 1.3$ minutes, respectively; the flow rate of cerebral perfusion was $10-12 \mathrm{~mL} / \mathrm{kg} / \mathrm{min}$ and pump pressure was $55-65 \mathrm{~mm} \mathrm{Hg}$; pressures in the left radial artery and distal LCA were $65-70$ and 50-60 mm $\mathrm{Hg}$, respectively; and bilateral cerebral oxygen saturation was $>70 \%$. Reconstruction of IA and LCA was completed in less than $7 \mathrm{mi}-$ nutes on average, during which the pressures of dorsal foot artery, left radial artery, and LCA measured 60-65, 70-75, and 50-60 $\mathrm{mm} \mathrm{Hg}$, respectively, whereas cerebral oxygen saturation did not change. The amount of blood loss and transfusion were $900 \pm 100$ and $870 \pm 100 \mathrm{~mL}$ on average. Mean time to awakening and extubation were $4.4 \pm 0.5$ and $19.2 \pm 4.4$ hours, respectively, and length of intensive care unit stay averaged $24.8 \pm 12.5$ hours. Neurocognitive function was normal in all patients. Neither stroke nor paraplegia occurred. Postoperative course was uneventful. Length 
TABLE 1. Patient profile, operative details, and early outcomes

\begin{tabular}{|c|c|c|c|c|c|c|}
\hline Variables & Case 1 & Case 2 & Case 3 & Case 4 & Case 5 & Summary* \\
\hline Age, y & 44 & 36 & 72 & 55 & 73 & $59.4 \pm 17.9$ \\
\hline Sex & Male & Male & Female & Male & Female & Male, $60 \%$ \\
\hline Weight, kg & 70 & 96 & 55 & 78 & 40 & $67.8 \pm 21.4$ \\
\hline BMI, $\mathrm{kg} / \mathrm{m}^{2}$ & 21.6 & 31.7 & 22.3 & 26.4 & 16.9 & $23.8 \pm 5.6$ \\
\hline Pathology & $\begin{array}{l}\text { Root aneurysm, } \\
\text { ICA from } \\
\text { false lumen }\end{array}$ & $\begin{array}{l}\text { Root aneurysm, } \\
\text { ICA from false } \\
\text { lumen, dominant } \\
\text { left vertebral artery }\end{array}$ & $\begin{array}{l}\text { Root aneurysm, } \\
\text { dominant left } \\
\text { vertebral artery }\end{array}$ & Root aneurysm & & $\begin{array}{l}\text { Root aneurysm, } \\
\quad 80 \%\end{array}$ \\
\hline Comorbidity & Hypertension & $\begin{array}{l}\text { Hypertension, } \\
\text { polycystic kidney, } \\
\text { chronic kidney } \\
\text { disease, obesity }\end{array}$ & $\begin{array}{l}\text { Hypertension, } \\
\text { chronic kidney } \\
\text { disease }\end{array}$ & Hypertension & $\begin{array}{l}\text { Six months post-total hip } \\
\text { replacement, pneumonia, } \\
\text { LAD stenosis }>80 \% \text {, } \\
\text { cachexia }(\mathrm{Hb} 6 \mathrm{~g} / \mathrm{dL} \text {, } \\
\text { albumin } 2.2 \mathrm{~g} / \mathrm{dL})\end{array}$ & $\begin{array}{l}\text { Hypertension, } \\
80 \%\end{array}$ \\
\hline HCA time, min & 3 & 2 & 2 & 3 & 3 & $2.6 \pm 0.5$ \\
\hline ACP time, $\min$ & 10 & 8 & 7 & 10 & 9 & $8.8 \pm 1.3$ \\
\hline CPB time, $\min$ & 224 & 216 & 234 & 219 & 269 & $232.4 \pm 21.6$ \\
\hline Cross-clamp time, min & 172 & 159 & 175 & 170 & 167 & $168.6 \pm 6.1$ \\
\hline Lowest temperature, ${ }^{\circ} \mathrm{C}$ & 25 & 28 & 27 & 26 & 25 & $26.2 \pm 1.3$ \\
\hline Blood loss, mL & 1000 & 800 & 1000 & 800 & 900 & $900.0 \pm 100.0$ \\
\hline Blood transfusion, $\mathrm{mL}$ & 1200 & 650 & 900 & 800 & 800 & $870.0 \pm 204.9$ \\
\hline Time to awakening, $\mathrm{h}$ & 4 & 5 & 5 & 4 & 4 & $4.4 \pm 0.5$ \\
\hline Time to extubation, $\mathrm{h}$ & 24 & 16 & 16 & 16 & 24 & $19.2 \pm 4.4$ \\
\hline Length of ICU stay, h & 39 & 16 & 15 & 16 & 38 & $24.8 \pm 12.5$ \\
\hline Length of stay, $d$ & 14 & 12 & 12 & 8 & 14 & $12.0 \pm 2.4$ \\
\hline
\end{tabular}

$B M I$, Body mass index; ICA, intercostal arteries; $L A D$, left anterior descending coronary artery; $H b$, hemoglobin; $H C A$, hypothermic circulatory arrest; $A C P$, antegrade cerebral perfusion; $C P B$, cardiopulmonary bypass; $I C U$, intensive care unit. *Values in the summary column are expressed as mean \pm standard deviation or percentage.

of stay averaged $12.0 \pm 2.4$ days (Table 1). All patients were alive at mean follow-up of $9.1 \pm 4.3$ months (range 4-13). Aortic computed tomography at 1 to 3 months showed obliterated false lumen and patent arch branches, without endoleak or distal new entry.

Informed consent was obtained from all patients for the publication of the study data.

\section{DISCUSSION}

Currently, neither the unilateral nor bilateral cerebral perfusion strategy ${ }^{2,5}$ addresses the issue of reverse left vertebral artery (LVA) or LCA steal secondary to proximal LSA clamping, whereby blood flow in upper spinal cord, posterior, and even anterior cerebral circulation is bypassed to the left arm and even the lower body. ${ }^{2,6}$ This is particularly detrimental in patients with a predominant LVA, anomalies of circle of Willis, or intercostal arteries arising from false lumen. Our method of cerebral perfusion via the LSA and RAA can maintain continuous antegrade blood flow in the right carotid artery and bilateral vertebral arteries and eliminate steal from the LVA and posterior communicating artery, providing more collateral flow to the left anterior circulation. The use of an FET with an unstented proximal graft avoids the need for distal anastomosis, which, together with clamping the arch at the LSA orifice, decrease the HCA time to as short as less than 3 minutes, permitting earlier resumption of perfusion to the spinal cord, viscera, and lower extremity. Sequential aortic reconstruction, usually taking 5 to 7 minutes for arch vessels, improves brain and myocardial protection.

Favorable anatomy is a key to our technique, which requires enough normal aortic tissue in the greater curvature and sufficient aortic tissue to clamp at the level of the LSA. In larger patients and those with obesity, the exposure and suture of the LCA may be difficult, especially in the setting of acute type A dissection. Cannulation of 3 arterial sites is more technically complex, which may be inappropriate for unstable patients, with potential risk of arterial injury and malperfusion. Despite that neither postoperative bleeding nor FET migration occurred in this preliminary 
experience, the efficacy of eliminating the distal anastomosis warrants validation in more patients over a long period of time.

Despite the concerns on the technical complexity, the risk-benefit ratio and the efficacy of cerebral perfusion via left subclavian and right axillary cannulation, our approach may represent an important step toward "optimum" organ-protection strategy in aortic arch surgery, which improves the perfusion to the left hemisphere while significantly shortens the duration of hypothermic circulatory arrest and antegrade cerebral perfusion. Further investigation in a large patient population for longer durations of follow-up, preferably in a multicenter setting, is warranted to validate the efficacy and durability of this technique.

The authors thank Dr Salvior C. M. Mok from ThedaCare for narrating the video.

\section{References}

1. Ma WG, Chen Y, Zhang W, Li Q, Li JR, Zheng J, et al. Extended repai for acute type A aortic dissection: long-term outcomes of the frozen elephant trunk technique beyond 10 years. J Cardiovasc Surg (Torino). 2020;61: 292-300.

2. Matalanis G, Shi WY. An Australian experience with aortic arch replacement: novel approach without circulatory arrest or deep hypothermia. Heart Lung Circ. 2011;20:163-9.

3. Ma WG, Zhu JM, Zheng J, Liu YM, Ziganshin BA, Elefteriades JA, et al. Sun's procedure for complex aortic arch repair: total arch replacement using a tetrafurcate graft with stented elephant trunk implantation. Ann Cardiothorac Surg. 2013; 2:642-8.

4. Zhu JM, Qi RD, Chen L, Liu W, Li CN, Fan ZM, et al. Surgery for acute type A dissection using total arch replacement combined with stented elephant trunk implantation: preservation of autologous brachiocephalic vessels. J Thorac Cardiovasc Surg. 2015;150:101-5.

5. Norton EL, Wu X, Kim KM, Patel HJ, Deeb GM, Yang B. Unilateral is comparable to bilateral antegrade cerebral perfusion in acute type A aortic dissection repair. $J$ Thorac Cardiovasc Surg. 2020;160:617-25.e5.

6. Grocott HP, Ambrose E, Moon M. External carotid compression: a novel technique to improve cerebral perfusion during selective antegrade cerebral perfusion for aortic arch surgery. Can J Anaesth. 2016;63:1179-83. 